\title{
Results of surgical and percutaneous ablative therapy for hepatocellular carcinoma in elderly patients
}

\author{
F Selvaggi*, D Risio, R Dimalio, C Cellini, D Simo, R Cotellese, M Legnini, P Innocenti \\ From de Senectute: Age and Health Forum \\ Catanzaro, Italy. 5-7 December 2009
}

\section{Background}

Liver resection is a curative treatment for hepatocellular carcinoma (HCC) [1]. Its role for the elderly remains undefined. In addition to surgery, percutaneous procedures have recently been proposed [2,3]. The choice of surgical and non-surgical therapy closely depends on the liver functional reserve and pre-existing co-morbidities.

\section{Materials and methods}

A retrospective analysis of a geriatric population $(\geq 65$ years) with HCC was proposed (July 2000-September 2009). Morbidity, survival, and recurrence rate were evaluated.

\section{Results}

A cohort of 45 Child-Pugh class A or B patients was collected. Of these, twenty-seven underwent surgery (male/female, 22/5; mean age 70). For 18 cases transcatheter arterial embolization (TACE), radiofrequency ablation (RFA), and portal vein embolization (PVE) (male/female, 15/3; mean age 74) were indicated (see Figure 1). Twenty patients with hepatitis $C$ infection, 7 with hepatitis B infection, 2 with both infections, 2 with alcoholic disease, and 14 with unknown etiology. The mean tumor size in the surgical group was $4.41 \mathrm{~cm}$, range 1,2 $-12 \mathrm{~cm}$; in the non-surgical cohort the size was $6,31 \mathrm{~cm}$, range $3-11,5 \mathrm{~cm}$. Twenty-eight unifocal and 17 multinodular tumors. We reported the aminotransferase serum variation after surgery and the tumor histology (see Figure 2). One patient died from liver failure. Nonlethal complications occurred in 21 patients. One case of biliary fistula and 1 intra-abdominal bleeding. The mean overall survival after surgery was 50 months. For ablative procedures was 26 months. The disease-free survival was in media 32 months the for surgical group and 18 months for the non-surgical group. Kaplan-Meier curves show the statistical significance (see Figure 3).

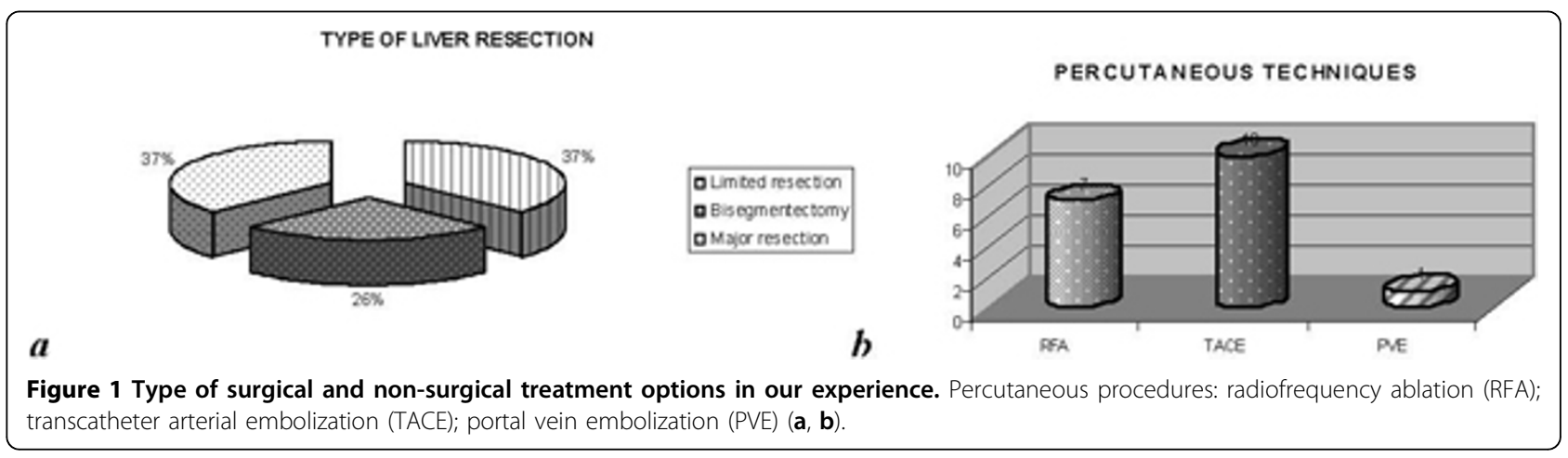

Surgical Sciences Department, "G. d'Annunzio" University Chieti-Pescara, Via

dei Vestini 66100, Chieti, Italy 

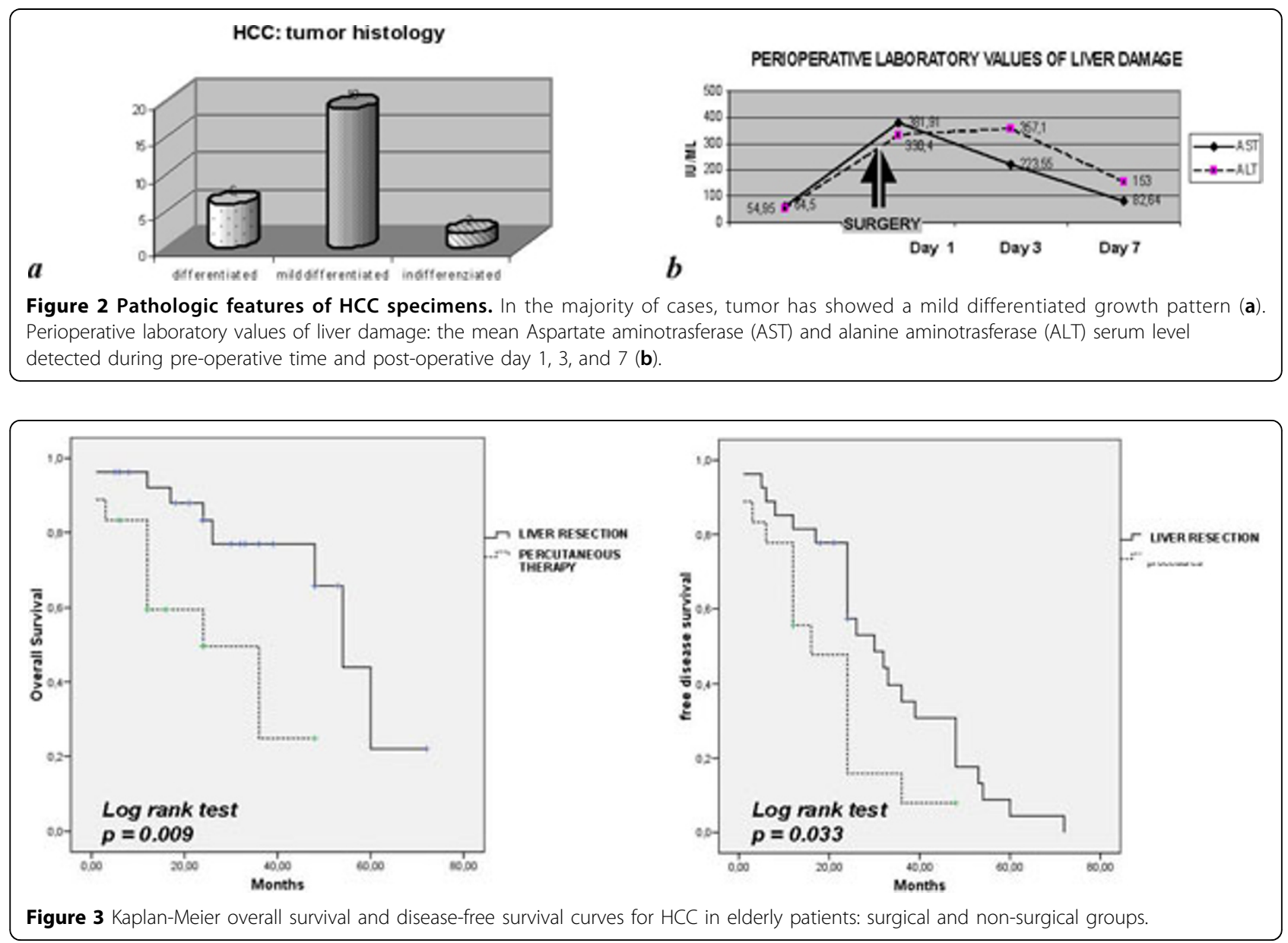

\section{Conclusions}

The role of liver resection for HCC is debated in the elderly. This is related to the short life expectancy and improvement of percutaneous procedures. These seem to guarantee similar overall survival compared to surgery. Unfortunately, this was not demonstrated from our data. With the improvement of surgical and anesthesia support, mortality has been significantly reduced. We performed liver resections in selected cases and our experience confirms the surgical benefits in elderly population.

Published: 19 May 2010

\section{References}

1. Nuzzo G, Giuliante F, Gauzolino R, Vellone M, Ardito F, Giovannini I: Liver resections for hepatocellular carcinoma in chronic liver disease: experience in an Italian centre. Eur J Surg Oncol 2007, 33:1014-1018.

2. Lupo L, Panzera P, Giannelli G, Memeo M, Gentile A, Memeo V: Single hepatocellular carcinoma ranging from 3 to $5 \mathrm{~cm}$ : radiofrequency ablation or resection? HBP 2007, 9:429-434.

3. Belghiti J, Kianmanesh R: Surgical treatment of hepatocellular carcinoma. HPB 2005, 7:42-49.
doi:10.1186/1471-2318-10-S1-A35

Cite this article as: Selvaggi et al: Results of surgical and percutaneous ablative therapy for hepatocellular carcinoma in elderly patients. BMC Geriatrics 2010 10(Suppl 1):A35.

\section{Submit your next manuscript to BioMed Central} and take full advantage of:

- Convenient online submission

- Thorough peer review

- No space constraints or color figure charges

- Immediate publication on acceptance

- Inclusion in PubMed, CAS, Scopus and Google Scholar

- Research which is freely available for redistribution 